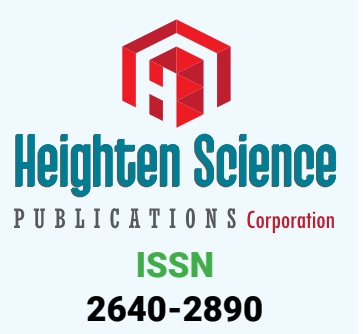

*Address for Correspondence: Benish Khanzada, Assistant Professor, Department of Obstetrics \& Gynecology, QIMS, FC Hospital, Quetta, Pakistan, Email: Khanzbiyaa@gmail.com

Submitted: 29 November 2018

Approved: 26 December 2018

Published: 27 December 2018

Copyright: @ 2018 Khanzada B, et al. This is an open access article distributed under the Creative Commons Attribution License, which permits unrestricted use, distribution, and reproduction in any medium, provided the original work is properly cited

Keywords: Postpartum; Intrauterine contraceptive device; Infection; Expulsion and perforation

Check for updates

\section{Immediate postplacental insertion of intrauterine contraceptive device (copper 375) and its complications in term of expulsion, infection and perforation}

\author{
Benish Khanzada ${ }^{1 *}$, Mala Jitendra Shahani ${ }^{2}$ and Areesha \\ Kamran Khanzada ${ }^{3}$ \\ 'Assistant Professor, Department of Obstetrics \& Gynecology, QIMS, FC Hospital, Quetta, Pakistan \\ ${ }^{2}$ MBBS, FCPS, CHK, Karachi, Pakistan \\ ${ }^{3}$ MBBS, MCPS, Akuh, Karachi, Pakistan
}

\section{Abstract}

Objective: To determine the complications (infection, perforation and expulsion rate) of immediate postplacental insertion of intrauterine contraceptive device (Multiload Copper375) in postnatal patients.

Methods: A case series study was conducted between October 28, 2014 to April 30, 2018 in obstetrics and gynaecology department, Civil Hospital Karachi,-+ Informed consent was taken. Intrauterine contraceptive device (Multiload) was inserted immediately within $10 \mathrm{~min}$ after delivery of placenta. These women were observed to determine outcome (infection, perforation and expulsion) at the time of discharge and 6 weeks postpartum. Absence of all these were taken as satisfactory outcome.

Results: A total of 435 women were included in this study. $165(38 \%)$ were delivered through cesarean section and $270(62 \%)$ were delivered through vaginally. There were $36(8.3 \%)$ cases of infection. The cumulative rate of expulsion and perforation at the end of sixth week of post insertion was $39(9 \%)$ and $0 \%$ respectively and $360(82.8 \%)$ had satisfactory outcome. Post-placental placements during cesarean delivery are associated with lower expulsion rates than post-placental vaginal insertions without increasing rates of postoperative complications like perforation, slightly increase infection rate following vaginal delivery.

Conclusion: Immediate postpartum insertion of IUCD is an effective, safe and easily reversible method of contraception. Rates of the complications (Infection, expulsion and perforation) are remarkably low.

\section{Introduction}

Pakistan stands as the six largest populated country in the world with a population of 197.02 million estimated in 2017. It is projected to contribute $2.63 \%$ to world's population in 2018 [1]. Average total fertility rate is 3.07 children, Contraceptive prevalence rate is $30 \%$ among which IUCD usage is only $2 \%$ [2].

In a data from recent Demographic and Health Surveys (DHS) conducted in 21 low- and middle-income countries to examine patterns of inter-pregnancy intervals, unmet need, $61 \%$ of women in 0-23 months postpartum have an unmet need for family planning [3].

How to cite this article: Khanzada B, Shahani MJ, Khanzada AK. Immediate postplacental insertion of intrauterine contraceptive device (copper 375) and its complications in term of expulsion, infection and perforation. Clin J Obstet Gynecol. 2018; 1: 082-086. https://doi.org/10.29328/journal.cjog.1001014 
An intrauterine device (IUD) is the most widely used method of contraception with approximately $14.3 \%$ of female contraceptive users prefer the IUD, globally [4,5]. 2 It is coitus-independent, reversible and effective form of contraception with immediate contraceptive action and have advantages: ease of insertion, minimal adverse impacts on breast feeding and cost effectiveness [6,7].

The postpartum period is potentially an ideal time to begin contraception as women are more motivated to do so at this time, which also has the advantage of being convenient for both patients and health care providers [8]. A descriptive study from Turkey reported expulsions in 235 women who had immediate post placental insertion of IUCD following either vaginal or caesarean delivery, combined expulsion rates were $5.1 \%, 7.0 \%$ and $12.3 \%$ at $1.5,6$ and 12 months respectively [9]. One case control study at JPMC Karachi examined 100 women who had post placental IUCD insertion. Follow up study was done at 1 week, 6 weeks and 6 months. Wound was infected in $10 \%$, heavy lochia in $2 \%$, at 6 months thread was visible in $92 \%$ and no perforation seen [10]. Another retrospective study from India in 300 women with immediate IUCD insertion reported lower abdominal pain (11.5\%), menorrhagia (6.6\%) dislodgment of IUCD (3.3\%) and expulsion (6.6\%) [11].

The aim of this study is to assess the effectiveness and safety profile of postpartum IUCD so that it can be recommended as an effective method of family planning.

\section{Materials and Methods}

This prospective, case series, study was carried out between October 28, 2014 to April 30, 2018 in the Department of Obstetrics and Gynecology, civil hospital Karachi. 435 pregnant women were included in the study through non probability consecutive sampling technique. The women with aged 18-35 and P2+0 OR more who requested postpartum contraception and delivered after 37 weeks of gestation (gestational age calculated by $1^{\text {st }}$ trimester scan), either vaginally or caesarean section were included in study. Women with signs of uterine infection (like foul smelling vaginal discharge, history of pre labour rupture of membrane $>8 \mathrm{hrs}$ ), preterm labour $(<37$ weeks gestation), uterine abnormalities or with history of ectopic pregnancy and postpartum hemorrhage were excluded from study. The sample size was calculated by using open-epi sample size calculator $\mathrm{P}=40 \%$, Confidence Interval 95\%, $\mathrm{d}=8 \%$. Informed consent was taken. Intrauterine contraceptive device (Multiload) was inserted immediately within 10 min after delivery of placenta. Outcomes were assessed in terms of infection, perforation and expulsion rate. Safety was defined by absence of infection and perforation. Infection was assessed on the basis of fever (Temp $100 \mathrm{~F}$ ) and foul smelling vaginal discharge within $1^{\text {st }}$ week of insertion. Dislodgment of device outside uterine cavity was regarded perforation positive and assessed by ultrasound pelvis and abdomen followed by X-ray abdomen after 6 weeks. Expulsion was assessed by absence of thread on per vaginal examination followed by ultrasound at 6 weeks period. Outcome was labeled satisfactory if there was absence of infection, perforation and expulsion at the end of 6 weeks period. This information was entered in semi structured proforma by researcher. Data entry and analysis was done by using computer software SPSS version 17.0. Quantitative variables like age and parity were presented by mean \pm SD. Qualitative variables like mode of delivery; infection, expulsion, and perforation were presented by frequency and percentages. Stratification was done with regard to type of delivery, age and parity to see the effect of them on outcome. For categorical variables (expulsion, infection and perforation) Chi-Square was done. The level of statistical significance was $\mathrm{P}<0.05$.

\section{Results}

A total of 435 women were included in this study. The age of the women ranged from 18-35 years. The average age of the women was $29.5+7.9$ and mean parity of women was $2.9+0.8 .165(38 \%)$ were delivered through cesarean section and $90(62 \%)$ 
were delivered through vaginally. There were 36 (8.3\%) cases of infection, cumulative rate of expulsion and perforation at the end of sixth week of post insertion was 39 $(9 \%)$ and $0 \%$ respectively and $360(82.8 \%)$ had satisfactory outcome (Table 1$)$. When outcome variables and satisfactory outcome were stratified with respect to mode of delivery, Post-placental placements during cesarean delivery are associated with lower expulsion rates (3.4\%) than post-placental vaginal insertions (5.5\%), without increasing rates of postoperative complications like perforation but slightly increase infection rate after vaginal delivery (6.2\%) than cesarean section (2\%) (Table 2).

\section{Discussion}

Insertion of an intrauterine contraceptive device (IUD) immediately after delivery has been recommended for long term temporary contraception. In the immediate post delivery period the women are highly motivated and need an effective method for contraception so that the child can be brought up with a relaxed mind without the worry of unintended pregnancy. On the other hand, if they are made to wait for 6 week for initiating an effective contraception, they may conceive accidentally or may not come for contraception. Postpartum women is particularly important because they often have a higher unmet need for family planning, but may not perceive themselves to be at risk because their menses have not returned and/or they are breastfeeding [12]. This approach is more applicable to our country where delivery may be the only time when a healthy woman comes in contact with health care personnel. Compared with sterilization, however, use of an intrauterine device (IUD) is simpler, less expensive, and immediately reversible. Insertion of an IUD after delivery may avoid the discomfort related to interval insertion, and any bleeding from insertion will be disguised by lochia. However, immediate post-partum IUD insertion may have disadvantages of spontaneous expulsion especially if post-delivery heavy vaginal bleeding.

In a systematic review by Kapp and Curtis [8], the outcomes of post-partum insertion of IUD at different time interval were compared. The evidence demonstrated no increase in risk of complications among women who had an IUD inserted during the post-partum period; however, some increase in expulsion rates occurred with delayed post-partum insertion when compared to immediate insertion. Expulsion rates were more when compared to interval insertion. IUCD is simpler, less expensive and immediately reversible. Copper containing IUCD does not interfere with breast feeding. Intrauterine contraceptive device is the second most common method of contraception used by women in regions with large population,

Including Pakistan [2]. It is favored by women who wish to use a contraceptive method that does not require regular motivation for use, husband participation and are not keen for using hormonal methods, ideally postpartum insertion should take place within 10 minutes of placental delivery or later till 48 hours of delivery [13-15].

Table 1: Outcome of immediate post placental insertion of intrauterine contraceptive device in postnatal patients.

\begin{tabular}{|c|c|c|}
\hline Outcome & frequency & Percentage \\
\hline Infection & 36 & $8.3 \%$ \\
\hline Expulsion & 39 & $9 \%$ \\
\hline Perforation & 0 & 0 \\
\hline Satisfactory Outcome & 360 & $82.8 \%$ \\
\hline
\end{tabular}

Table 2: Stratification of Outcome with respect to the mode of delivery.

\begin{tabular}{|c|c|c|c|c|}
\hline \multicolumn{2}{|c|}{ Outcome } & Cesarean section & vaginal & P-value \\
\hline \multirow{2}{*}{ Infection } & Yes & 09 & 27 & \multirow{2}{*}{0.536} \\
\cline { 2 - 5 } & No & 156 & 243 & \multirow{2}{*}{1} \\
\hline \multirow{2}{*}{ Expulsion } & Yes & 15 & 24 & \multirow{2}{*}{ NA } \\
\cline { 2 - 4 } & No & 150 & 246 & 0 \\
\multirow{2}{*}{ Perforation } & Yes & 0 & 189 & \multirow{2}{*}{0.008} \\
\hline \multirow{2}{*}{ Satisfactory Outcome } & No & 165 & 81 & \\
\hline
\end{tabular}


In our study all $(\mathrm{n}=435)$ women had IUCD insertion within 10 minutes of delivery of placenta. The cumulative expulsion rate at the end of 6 week was $8.3 \%$. This is comparable with a local study in which expulsion rate was 6\% [10]. This is also supported by studies conducted in Egypt and Saudi Arabia in which expulsion rate of $5 \%$ at the end of 1 year is reported [16]. another study by Levi et al study concluded $8 \%$ expulsion rate at 6 weeks following post placental insertion [17].

In our study, Post-placental placements during cesarean delivery are associated with lower expulsion rates (3.4\%) than post-placental vaginal insertions (5.5\%), similar to kapp and Curtis study [8], who found expulsion rate following Post-placental insertions during caesarean section were associated with lower expulsion rates than post-placental vaginal insertions without any increase in other complications (0.0$13.9 \%$ versus7.5-22.6\%).

In our study there were no postoperative complications like perforation in any mode of delivery but slightly increase infection rate after vaginal delivery $(6.2 \%)$ than caesarian section $(2 \%)$.

Advantages of immediate post-partum insertion include high motivation, assurance that the woman is not pregnant, and convenience. The popularity of immediate postpartum IUD insertion in countries as diverse as China, Mexico, and Egypt supports the feasibility of this approach. Early follow up may be important in identifying spontaneous IUD expulsions [4].

According to medical eligibility criteria WHO, immediate post-placental insertion of Copper $(\mathrm{Cu} \mathrm{T})$ is recommended in breast feeding as well as non-breast feeding mothers. It is safe and effective. Insertion after delivery of the placenta is associated with lower expulsion rates than delayed post-partum insertion. Additionally, postplacental placement at the time of caesarean section has lower expulsion rates than post-placental vaginal insertions. Insertion complications of perforation and infection are not increased by IUD placement at any time during the post-partum period $[14,15,18]$.

\section{Limitations}

There is a need for large randomized studies to compare the risks and complications of post-placental IUD insertion in special risk groups where there is increased risk of infection such as women with heart disease, diabetes, HIV positive women and patients who are on immunosuppressant's for autoimmune diseases. There are not much data from our country. We need to have more studies in different settings before we declare the post-placental IUD insertion completely safe.

\section{References}

1. Population of the world. 2018; Ref.: https://goo.gl/DakscN

2. Pakistan demographic and health survey. Ref.: https://goo.gl/XLqk7U

3. Dirk W, Norman DG. Reversible, Long-Action Reproductive Control with Frameless IUD for Intracesarean Insertion. J Gynecol. 2017; 2: 000S1005. Ref.: https://goo.gl/YYBGHd

4. Moore Z, Pfitzer A, Gubin R, Charurat E, Elliott L, et al. Missed opportunities for family planning: an analysis of pregnancy risk and contraceptive method use among postpartum women in 21 low- and middle-income countries. Contracept. 2015; 92: 31-39. Ref.: https://goo.gl/YDqexi

5. Wildemeersch D, Goldstuck ND, Hasskamp T. Current status of frameless anchored IUD for immediate intracesarean insertion. DEV pErioD mED. 2016; 20: 9-17. Ref.: https://goo.gl/XKAqom

6. Bühling KJ, Zite NB, Lotke P, Black K, INTRA Writing Group. Worldwide use of intrauterine contraception: a review. Contraception. 2014; 89:162-173. Ref.: https://goo.gl/ocHN9Z

7. Balasubramaniam S, Kumar S, Sethi R, Charurat E, Lalchandani K, et al. Quasi-experimental Study of Systematic Screening for Family Planning Services among Postpartum Women Attending Village Health and Nutrition Days in Jharkhand, India. Int J Integr Care. 2018: 18: 7. Ref.: https://goo.gl/UMQPkE 
8. Kapp N, Curtis KM. Intrauterine device insertion during the postpartum period: a systematic review. Contraception. 2009; 80: 327-326. Ref.: https://goo.gl/YX8hhb

9. Celen S, Moroy P, Sucak A, Akhtuly A, Danisman N. Clinical outcomes of early postplacental insertion intrauterine contraceptive devices. Contraception. 2004; 69: 279-282. Ref.: https://goo.gl/sTt7BE

10. Bhutta SZ, Butt IJ, Bano K. Insertion of Intrauterine Contraceptive Device at Caesarean Section. J Coll Physicians Surg Pak. 2011; 21: 527-530. Ref.: https://goo.gl/XEtQnM

11. Kittur S, Kabadi YM. Enhancing contraceptive usage by post placental intrauterine contraceptive devices (PPIUCD) insertion with evaluation of safety, efficacy and expulsion. Int J Reprod Contracept Obstet Gynecol. 2012; 1: 26-32. Ref.: https://goo.gl/ukgQBA

12. Tomar B, Saini V, Gupta M. Post-partum intrauterine contraceptive device: acceptability and safety. Int J Reprod Contracept Obstet Gynecol. 2018; 7: 2011-2017. Ref.: https://goo.gl/U4TgVF

13. Çelen Ş, Sucak A, Yııdız Y, Danışman N. Immediate postplacental insertion of an intrauterine contraceptive device during cesarean section. Contraception. 2011; 84: 240-243. Ref.: https://goo.gl/hdczEG

14. Lester F, Kakaire $\mathrm{O}$, Byamugisha J, Averbach S, Fortin J, et al. Intracesarean insertion of the Copper T380A versus 6 weeks postcesarean: a randomized clinical trial. Contraception. 2015; 91: 198-203. Ref.: https://goo.gl/wqWenN

15. Cleland, J, Shah, I and Benova, L. A fresh look at the level of unmet need for family planning in the postpartum period, its causes and program implications. Int Perspect Sex and Reprod Health. 2015; 41: 155-162. Ref.: https://goo.gl/jwHK6k

16. Ragab A, Hamed HO, Alsammani MA, Shalaby H, Nabeil H, et al. Expulsion of Nova-T380, Multiload 375, and Copper-T380A contraceptive devices inserted during cesarean delivery. Int J Gynaecol Obstet. 2015; 130: 174-178 Ref.: https://goo.gl/i1H1Ni

17. Levi EE, Stuart GS, Zerden ML, Garrett JM, Bryant AG. Intrauterine device placement during caesarean delivery and continued use 6 months postpartum: a randomized controlled trial. Obstet Gynecol. 2015; 126: 5-11. Ref.: https://goo.gl/63DA6i

18. TurokDK, Leeman L, Sanders JN, Thaxton L, Eggebroten JL, et al. Immediate postpartum levonorgestrel intrauterine device insertion and breast-feeding outcomes: a noninferiority randomized controlled trial. Am J Obstet Gynecol. 2017; 217: 665.e1-665.e8. Ref.: https://goo.gl/Qq5BYT 